\title{
Developing Cultural Competence as Part of Nursing Studies: Language, Customs and Health Issues
}

\author{
Mohammad Khatib ${ }^{1} \&$ Salam Hadid $^{1}$ \\ ${ }^{1}$ Zefat Academic College, Nursing department, Zefat, Israel \\ Correspondence: Mohammad Khatib, Zefat Academic College, Nursing department, Zefat, Israel.
}

Received: November 20, 2018

Accepted: January 2, 2019

Online Published: February 26, 2019

doi:10.20849/ijsn.v4i1.549

URL: https://doi.org/10.20849/ijsn.v4i1.549

\begin{abstract}
Introduction: Developing nurses' cultural competence begins with their basic training, and requires them to participate in an array of activities which raise their awareness and stimulate their interest, desire and curiosity to know about different cultures. The aim of this work is to evaluate a cultural competence teaching model for nursing students.
\end{abstract}

Method: A qualitative and quantitative evaluation was done using a semi-structured questionnaire completed by 155 students.

Results: An improvement in cultural awareness, knowledge and attitudes among students as well as their willingness to recognize the other's difference was noted. The qualitative evaluation raised 3 themes: attitude change, cultural intelligence improvement and exploring cultural similarities.

Conclusions: Developing nurses' cultural competence needs to be part of their basic training and based on cultural knowledge and experiential learning methods as well as providing them the opportunity to be exposed to different cultures.

Keywords: cultural nursing, language, nursing students, Jews, Arabs

\section{Introduction}

Cultural competence is defined as the process one goes through to continuously develop and refine one's capacity to provide effective health and social care, taking into consideration people's cultural beliefs, behaviors, and needs, as well as the effects that societal and organizational structures may have on them (Papadopoulos, 2006).

Competence is a process that combines acceptance of and respect for differences, and prevents the individual's beliefs from influencing those with different world views. Improving the quality of health professions, including nursing, is one of the most effective and critical interventions for improving health and reducing gaps in health within and among populations. In order to provide safe and effective care, caregivers must be aware of the health beliefs, values, norms, language, and decision-making processes of their patients which affect their health (Calvillo et al 2009).

Developing cultural competence requires a strong foundation in the professional education process that provides knowledge, a deep understanding of the problems, experiences and rules that promote students' involvement in a multicultural society, a commitment to ethical values and behaviors, appreciation of shared and different traditions, and awareness of the world and its problems (Anderson, 2004). Cultural competence includes awareness, knowledge, understanding, and sensitivity that recognize the uniqueness of each patient. Knowledge of the patient's cultural background enables appropriate, adapted and easier treatment (Cowan \& Norman, 2006). The caregivers who care for patients from different cultural groups experience the daily challenges of low health literacy, cultural barriers, and language disabilities that impose difficulties to providing effective treatment. In recent years, more and more attention has been given to the two main challenges, cultural differences and language barriers, and more awareness and vigilance are being promoted for the delivery of culturally and linguistically appropriate medical services (Singleton \& Krause, 2010).

Since a direct correlation exists between the degree of success of patient care and the quality of therapist and patient communication, differences of ethnicity, language or cultural values pose serious challenges to the 
development of therapeutic relationships and communication and the provision of culturally appropriate treatment (Samover \& Porter, 2004). Therefore, understanding the culture and the language is important for the development and promotion of effective communication that contributes to the health effective care. Effective communication combines the ability to create a common language and to understand the nuances in specific situations. This includes the knowledge of what to say and what not, what register to use (formal or informal; spoken or written) and what tone, voice and vocabulary to use.

Effective communication is a vital skill of health care professionals and perhaps the most important component of the nurse's work (Jagosh et.al, 2011). Guttman (2004) argues that linguistically cultural competence is a major component of general cultural competence because it involves the need for good and honest communication between the therapist and the patient. This has implications for the communication skills of caregivers, especially those who function in a culture that differs from their own culture and language.

Various models have been proposed to account for cultural competence and its components. Campinha-Bacote's process-oriented model presents a combination of five structures to be developed in the process of acquiring cultural competence: cultural awareness, cultural skills, cultural encounters, cultural knowledge and cultural desire (Campinha-Bacote, 2002).

Other models include that of Papadopoulos (2006), which posits two levels of cultural competence, general and specific, where each level consists of four components: cultural awareness, cultural knowledge, cultural sensitivity and cultural competence. Purnell's (2002) model presents cultural competence as a structure of three circles, the community, the family and the individual, where the general society is the framework that surrounds these circles.

One of the barriers to achieving cultural competence among nursing students is the lack of standards that determine which qualifications are required for each nurse (Ballantyne, 2008). In 2006, the American Association of Nursing Colleges (AACN) appointed a team of experts to work on developing standards for training nurses, including a standard for cultural competence. They determined that five types of abilities must be developed in the professional education of caregivers (acquisition of social and cultural knowledge, use of relevant sources of information, promotion of safety and quality of care, advocacy for social justice and ongoing partnership for the development and promotion of cultural competency) (AACN, 2008). One of the abilities is to provide and develop knowledge about the social and cultural factors that influence the treatment of different contexts. In addition, the committee recommended that the curriculum should be designed to train students to demonstrate understanding of culture, to discern similarities and differences in values, beliefs and skills, to explain the relationship between cultural, physical, environmental and hereditary factors and to integrate cultural information including language and health literacy into the nursing process. The three important characteristics that the caregivers should develop are, firstly, the awareness of the values, beliefs, attitudes, and cultural behaviors of each other; secondly, the ability and skill to identify and develop communication with individuals from different cultures; and thirdly, the ability to identify cultural variability for the process of assessment and nursing planning.

There are various ways of integrating cultural competence and its various components into nursing education programs, such as introducing the subject as an adjunct to existing teaching subjects, or developing independent courses in cultural competence (Davidhizar \& Giger, 2001; Worrell-Carlisle, 2005; Coleman, et al., 2005; Anderson, 2004). Students' cultural competence can be assessed on two levels. The first is that of the student's personal reporting of his cultural knowledge and the degree to which he has internalized the principles of cultural competence. The second is the level of observation in the field that examines the level of cultural competence that is actually reflected in the student's interactions with patients. Most of the tools available to examine or measure cultural competence are based on personal reporting and personal perception of this competency (AACN, 2008). But these do not always reflect the evaluation given by the patient. In spite of this limitation, it is valuable to examine changes in perception of cultural competence over time, and to identify the factors which influence these changes and which can form the basis for curriculum design and methods of teaching and learning. Kardong-Edgren and Campinha-Bacote (2008) conducted a study that used four methods to assess the effectiveness of cultural competency among four groups of nursing graduates, and the results showed that the main impact of the programs was on the level of awareness and alertness. Kardong-Edgren and others (2010), in a study comparing six different programs for developing culturally competent nurses, found that there is no particular program that is more effective than others for achieving cultural competence. Reyes, Hadley and Davenport. (2013) examined whether the self-efficacy perception of nursing students increased during their study period, and found that students felt they had become culturally competent as a result of the curricula they had been exposed to. Lipson and Desariti (2007) presented a set of methods used in various nursing programs to 
integrate content related to cultural competence during the course of studies. Some of the programs focused on knowledge, attitudes and skills using a variety of teaching methods such as focus groups, modeling and theory, simulations, distance learning, and brainstorming. Some of the programs were based on the theoretical models of Purnell, (2002), Giger \& Davidhaizar, (2002) and Campinha-Bacote, (2002; 2003).

\subsection{Promoting Cultural Competency in the Israeli Health System}

In recent years, the Ministry of Health in Israel has defined the issue of reducing health inequality as a strategic goal. It is widely felt that culturally appropriate treatment, as well as adaptation and cultural accessibility of health services, are important strategies for reducing existing health disparities between different population groups and regions and for improving health in general. As part of the efforts to reduce gaps and inequalities in health, the Administration for Etrategic and Economic Planning at the Ministry of Health has issued a booklet of guidelines and practices designed to assist health care professionals at the crossroads of policy and activity planning decisions that affect the resources and work methods of the organization in which they work (Avni and Averbuch, 2017, Lerner-Zechut, 2015).

In addition, in collaboration with the National Center for Medical Simulations (MSR), the administration has developed a training system that includes a variety of simulations that present multicultural encounters in the kind of therapeutic contexts which students and health professionals normally practice. The simulations are used as tools for discussion in training professionals in cultural competency. In recent years, cultural competency has been an important component of most nursing programs in Israel. To this end, training programs and training tools have been developed to promote the cultural competence of health professionals. In addition, one of the important steps taken in the context of the cultural and linguistic accessibility of health services is the health ministry CEO order for "Cultural and linguistic Adaptation and accessibility in the health system" published in 2011 (order No. 11/7). The order specifies guidelines that Israeli health institutions must implement in order to promote cultural and linguistic accessibility in health services, such as the obligation to translate orally into four languages (English, Arabic, Amharic and Russian), the obligation to translate documents into three languages, and providing translation services given by "cultural mediators".

\subsection{The Study Model in Zefat}

The Zefat Academic College is a regional college that serves mainly the population of northern Israel, which is culturally diverse. Approximately 1.3 million citizens of all religions and ethnic groups reside in the north: Jews and Arabs, Muslims, Christians, Druze and Circassians. The cultural diversity of the population is also reflected in the composition of the students in the college, in which about 2,500 students (41\% Jews, 59\% Arabs) study. Series of college activities are done in the context of multiculturalism such as staff workshops, workshops on multiculturalism and dialogue, pre-school language courses, extracurricular activities and number of degree courses for nursing, social work, and physiotherapy students.

About 300 students from a variety of national and religious groups study in the nursing department, the largest department in the college. The department's mission is to train and promote high-quality nurses who have cultural competence and the ability to provide an effective and quality care in a multicultural society. To this end, the department has developed an intervention model that emphasizes the cultural aspects of the core subjects together with specific courses for the development of the graduates' cultural competence.

The model implemented at the Zefat Academic College is based on Papadopoulos' cultural competency development model (Papadopulos, 2004) which combines two approaches. On the one hand, a number of courses that are part of the core curriculum include cultural aspects as a central component, such as interpersonal communication, patient training, and nursing diagnosis. On the other hand, independent courses are held that deal with multicultural nursing and cultural competence on the theoretical, applied and research levels.

In this context, a course in transcultural nursing is given as a compulsory course for third year students. The theoretical section deals with the concept of culture and its components, with reference to Israeli cultures, and reviews theories and models for the development of cultural competence. The course also includes practical activities in which students make presentations and learn about cultural values, symbols, customs, and their own and others' cultural heritages in health contexts. In addition, various simulations of multi-cultural therapy sessions are presented using video clips prepared by the Ministry of Health and MSR, (2014), followed by comprehensive discussions. In the applied field, the course "Clinical terminology and spoken languages" (Zafrir \& Nissim, 2011), deals with learning and developing verbal communication in the use of the major languages spoken in Israel. The purpose of the course is to increase students' knowledge of the importance of language, its origins and its development, to illustrate the importance of language barriers as obstacles to quality treatment and to improve communication between students and patients with different cultural backgrounds. Students are given 
the opportunity to acquire verbal skills in a number of languages spoken in Israel (apart from Hebrew) such as Arabic, Russian, Amharic and Yiddish. In 2017, the two additional languages studied were Circassian and sign language. Mainly the students themselves manage the course and they teach their fellow classmates using various methods such as videos, role-playing games, quizzes, simulations and exercises.

At the research level, a seminar of qualitative research on multicultural nursing for fourth year students, whose goal is to instill and implement the multicultural approach to promoting the health of ethnically and culturally heterogeneous populations based on theories in transcultural nursing (Leininger, 2002; Leininger \& McFarland, 2002). Within the framework of the seminar, specific local cultural groups and health issues (health situations, health behaviors and professional dilemmas) are chosen, and in-depth qualitative research relating to cultural issues is carried out. Students are required to collect information about the cultural group and their research topic in both the general and the specific cultural context (etic) using cultural assessment tools learned in the theoretical courses of transcultural nursing (Leininger, 2002; Giger \& Davihizar, 2008). In addition, they conduct in-depth interviews to collect information from the perspective of the culture selected (emic). Based on their findings, students are also required to propose an action plan based on theories they have studied whose goal is to improve health in the specific context under study, while respecting the cultural uniqueness of the target population.

This article presents the evaluation of the study model (both courses, transcultural nursing and languages) from both the theoretical and the practical points of view. At the same time, it examines the influence of the learning process on the students' cultural knowledge, awareness of their own culture and other cultures, the perceived contribution to their cultural competence, and the major differences between students of different origins. Both quantitative and qualitative tools were used in the assessment.

\section{Method}

At the end of the courses, 156 students answered the two evaluation questionnaires for both courses $(\mathrm{N}=105$ for transcultural nursing; $\mathrm{N}=51$ for spoken languages) (Table 1). The questionnaires were prepared by the course coordinator and included questions about personal details such as gender, age, religion, and ethnicity, as well as questions about the contribution of the intervention to knowledge of their own and other cultures, awareness of the other, cultural sensitivity, and changes in attitudes towards their own and other cultures. The students were asked to indicate the extent of the contribution of each factor on a Likert scale where $1=$ very high; $5=$ did not contribute at all, and in a number of open questions were asked to explain their change in attitudes, insights and suggestions for change and improvement. For the spoken languages course, quantitative and qualitative measures were used to ask students about acquiring new vocabulary and the extent to which the course contributed to improving communication with their patients. Informed consent was received for completing the questionnaire and publishing the data.

Table 1. Distribution of students by gender, ethnicity and religion

\begin{tabular}{lrcccc}
\hline & & \multicolumn{2}{c}{ Transcultural Nursing course } & \multicolumn{2}{c}{ Language course } \\
& & N & \% & N & \% \\
\hline Total & & 105 & 100 & 51 & 100 \\
Gender & Males & 32 & 30.5 & 12 & 23.5 \\
& Females & 73 & 69.5 & 39 & 76.5 \\
Ethnicity & Jews & 46 & 43.8 & 22 & 43.1 \\
& Arabs & 59 & 56.2 & 29 & 57.0 \\
Religion & Jewish & 44 & 41.9 & 21 & 41.2 \\
& Moslems & 45 & 42.9 & 25 & 49.1 \\
& Christians & 8 & 7.6 & 2 & 3.9 \\
& Druze & 6 & 5.7 & 2 & 3.9 \\
& Other & 2 & 1.9 & 1 & 1.9 \\
\hline
\end{tabular}

\section{Results}

\subsection{Quantitative Assessment}

A quantitative assessment was carried out on the data regarding the extent to which the theoretical part of the courses contributed to the students' knowledge, attitudes, and cultural sensitivity. In addition, the special contribution of the interactive part of these courses was evaluated. 
$41.0 \%$ of the students said there was a great improvement in their general cultural knowledge following the transcultural nursing course. The learning process improved students' cultural knowledge about other cultures; $75.2 \%$ reported improvement of a high to very high degree.

The course contributed to the improvement of cultural sensitivity in a therapeutic encounter they experienced at their current stage of clinical experience in the field. About half of the students reported that the courses contributed greatly to their level of cultural sensitivity at this meeting (Figure 1).

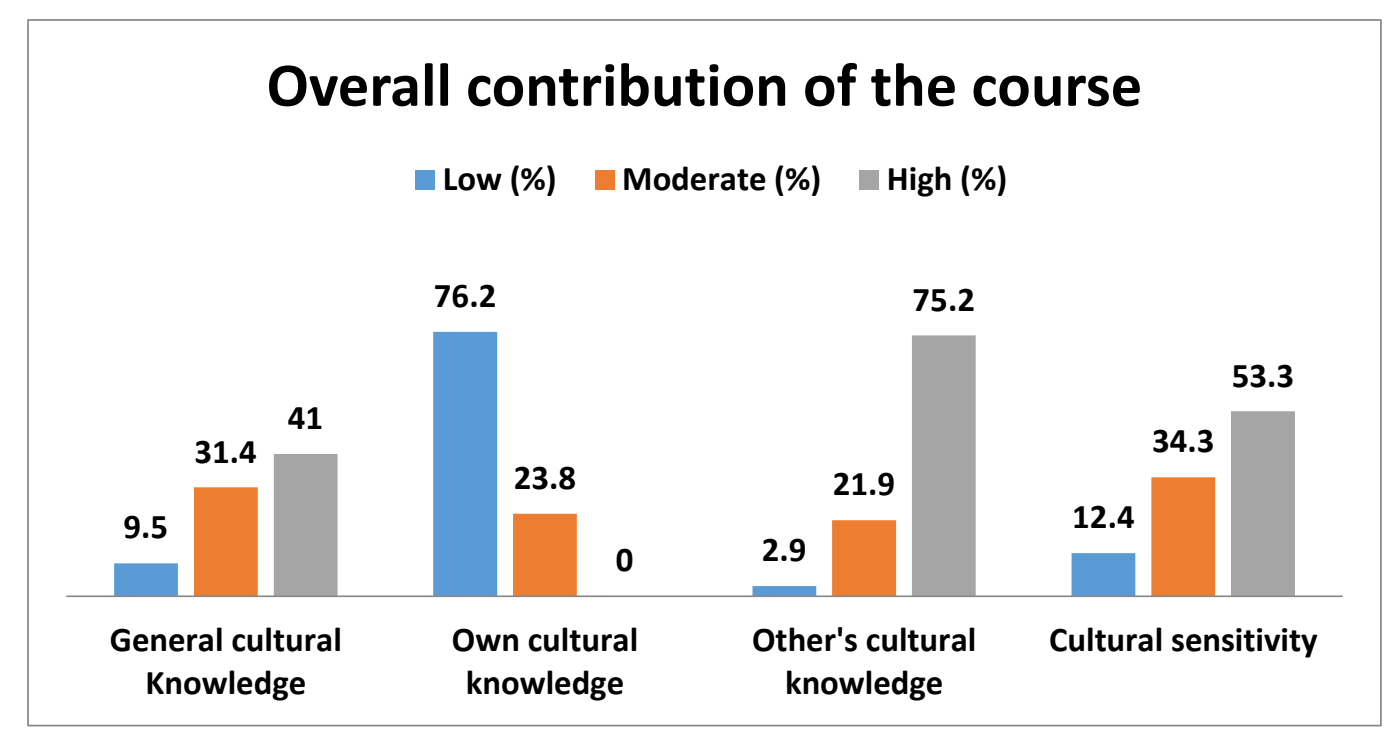

Figure 1. The overall contribution of a transcultural nursing course

$66.1 \%$ of Arab students said that their general cultural knowledge had improved significantly, compared to 50\% of the Jewish students following the transcultural nursing course (Table 2). In addition, Arab students learned more about their own culture than Jewish students (30.5\% versus $15.2 \%$ ) did. Most of the students, Jews and Arabs, reported an improvement in their knowledge of other cultures (76.1\% and $74.6 \%$, respectively). $57.6 \%$ of the Arab students reported that the transcultural nursing course contributed to the improvement of cultural sensitivity (compared to $47.8 \%$ of the Jewish students).

Table 2. The general contribution of transcultural nursing course to students by ethnicity

\begin{tabular}{lcccccc}
\hline & \multicolumn{2}{c}{$\begin{array}{c}\text { Low } \\
(\boldsymbol{\%})\end{array}$} & \multicolumn{2}{c}{$\begin{array}{c}\text { Moderate } \\
(\boldsymbol{\%})\end{array}$} & \multicolumn{2}{c}{$\begin{array}{c}\text { High } \\
(\boldsymbol{\%})\end{array}$} \\
& Jews & Arabs & Jews & Arabs & Jews & Arabs \\
\hline General cultural Knowledge & 17.4 & 3.4 & 32.6 & 30.5 & 50 & 66.1 \\
own cultural Knowledge & 84.8 & 69.5 & 15.2 & 30.5 & 0 & 0 \\
other's cultural Knowledge & 6.5 & 0 & 17.4 & 25.4 & 76.1 & 74.6 \\
Cultural sensitivity & 17.4 & 8.5 & 34.8 & 33.9 & 47.8 & 57.6 \\
\hline
\end{tabular}

$41.9 \%$ of the students (45.8\% of Arabs vs. $37.0 \%$ of Jews) reported on change of their general attitudes towards others' culture. Arab students, more than Jewish said thy change attitudes towards their own culture $(16.9 \%$ and $4.3 \%$ respectively). (Figure 2 ).Figure 2 : Student attitude change by ethnicity 


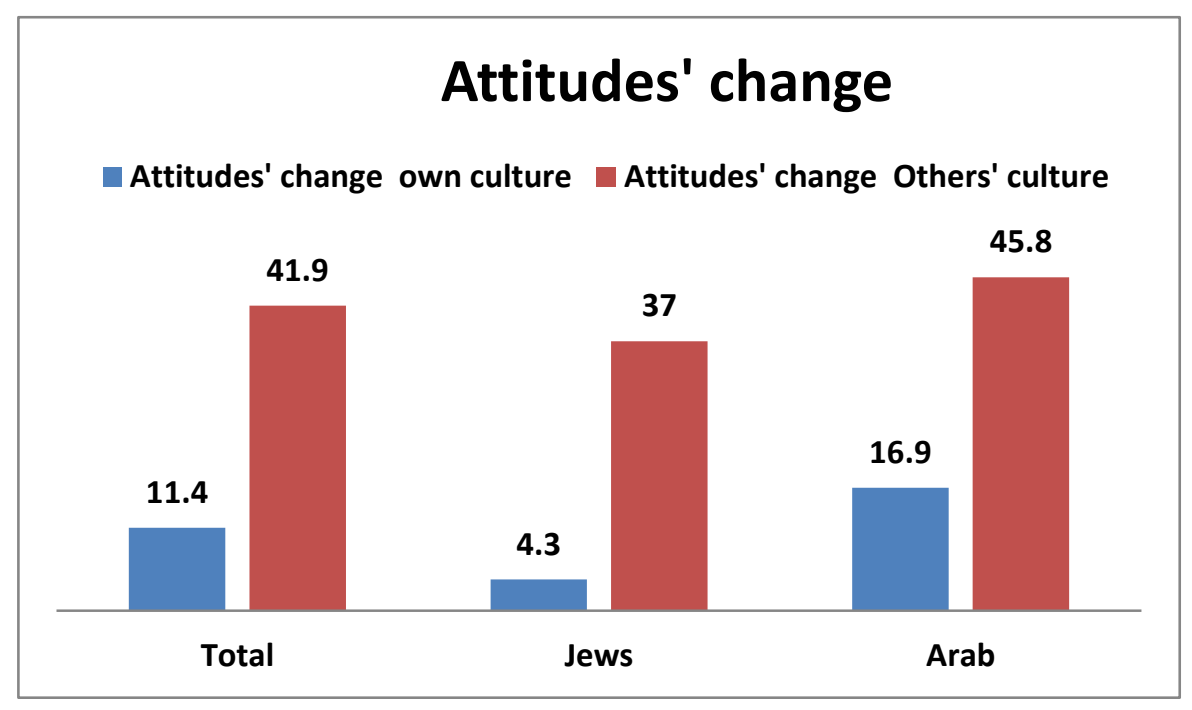

Figure 2

In the course, students presented cultural events and customs from their own cultures, explaining the sources and meaning of these events and customs with reference to health using visual aids (videos, pictures, and illustrations). $20.2 \%$ of the students reported that they were exposed to information they had not previously known about their own culture (Figure 3).

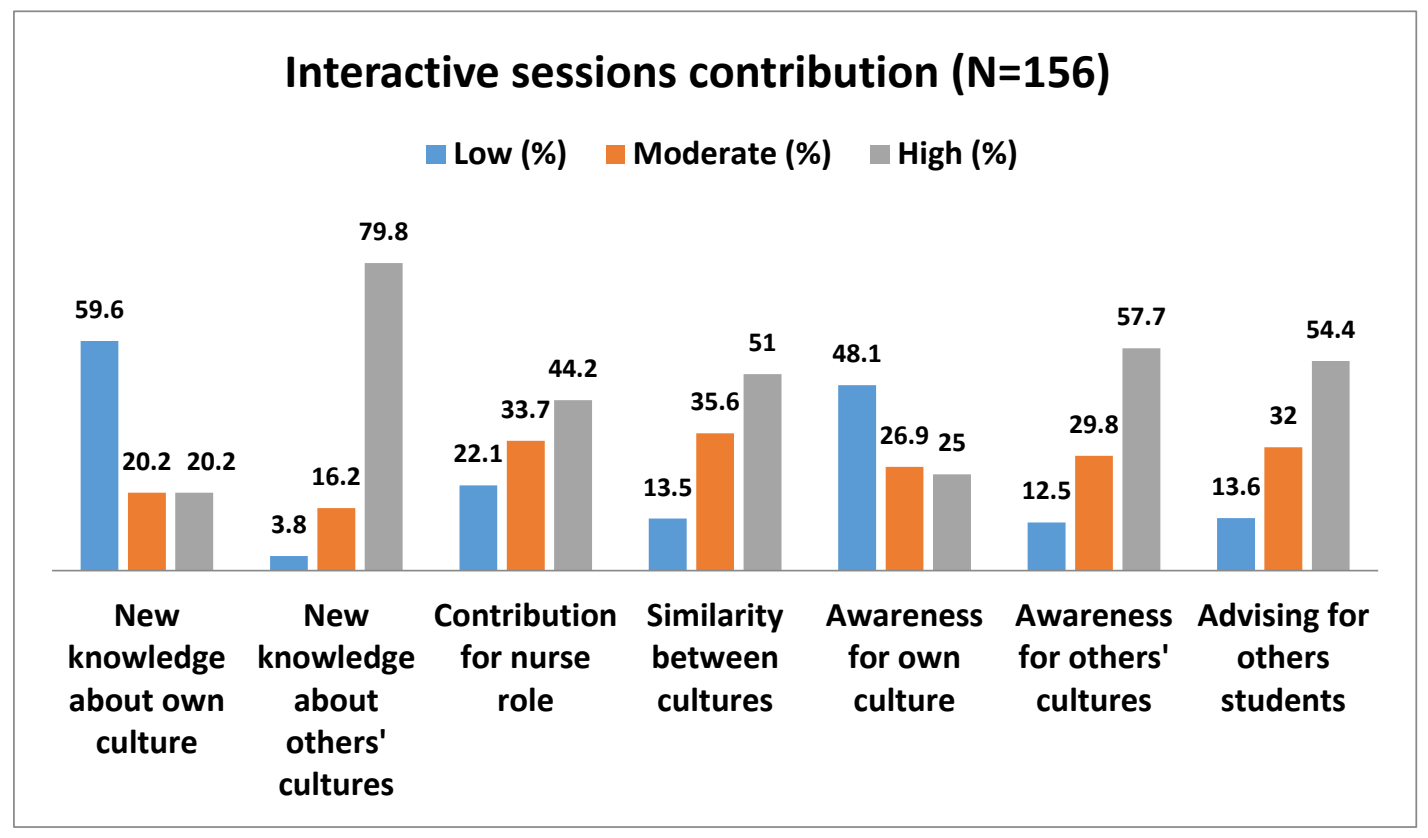

Figure 3. Interactive session contribution

More Arab students than Jews reported that they had learned more about their own culture (25.9 versus 13.0). Most of the learning was about other cultures. $79.8 \%$ (81\% Arabs and $78.3 \%$ Jews) said that the activity added new information about other cultures. $44.2 \%$ of the students said that the activity greatly contributed to their role as nurses. In addition, more than half the students (57.7\%) reported an improvement in their level of awareness of the culture of others and their own culture (25.0\%). More than half reported having discovered a great deal of similarity between their own and other cultures. $86.4 \%$ of the students reported that they would recommend the course to other students. 
Table 3. Interactive session contribution by ethnicity

\begin{tabular}{lcccccc}
\hline & \multicolumn{2}{c}{$\begin{array}{c}\text { Low } \\
(\%)\end{array}$} & \multicolumn{2}{c}{$\begin{array}{c}\text { Moderate } \\
(\%)\end{array}$} & \multicolumn{2}{c}{$\begin{array}{c}\text { High } \\
(\%)\end{array}$} \\
& Jews & Arabs & Jews & Arabs & Jews & Arabs \\
\hline New knowledge on own culture & 71.1 & 5 & 15.2 & 24.1 & 13 & 25.9 \\
New knowledge on others' cultures & 4.3 & 3.4 & 17.4 & 15.5 & 78.3 & 81 \\
Contribution to nurse's role & 37 & 10.3 & 32.6 & 34.5 & 30.4 & 55.2 \\
Similarity between cultures & 15.2 & 12.1 & 41.3 & 31 & 43.5 & 56.9 \\
Awareness of own culture & 69.6 & 31 & 17.4 & 34.5 & 13 & 34.5 \\
Awareness of others' cultures & 19.6 & 6.9 & 34.8 & 25.9 & 45.7 & 67.2 \\
Recommending to other students & 13 & 14 & 50 & 17.5 & 37 & 68.4 \\
\hline
\end{tabular}

For the course on spoken languages and medical terminology, the assessment was made by examining the contribution to students' general knowledge of different languages through their mother tongue, improving the ability to develop more effective communication with the patients, enriching vocabulary in languages other than their own, and improving cultural competence in general. $72.5 \%$ said that the course improved to a moderate or very high degree their knowledge of other languages and their ability to develop more effective communication, $68.6 \%$ reported moderate to very great improvement in their vocabulary, and $76.5 \%$ reported an improvement in their level of cultural competence (Figure 4).

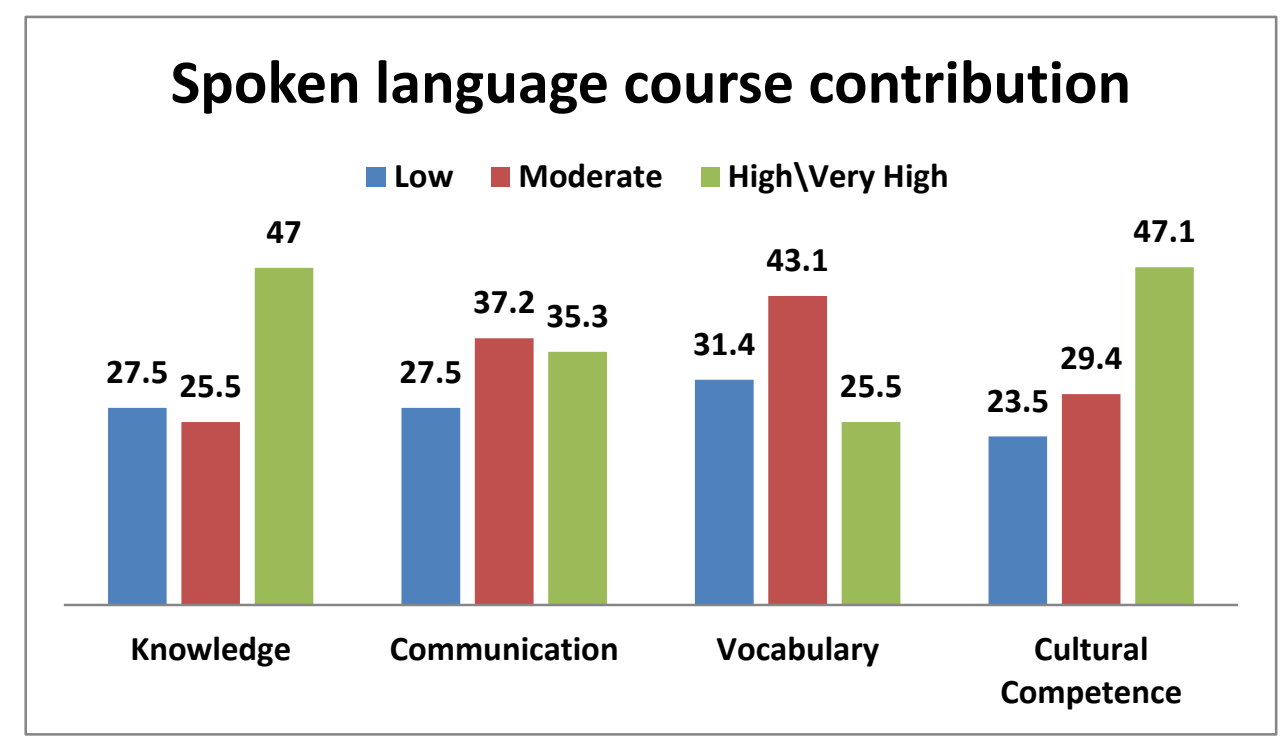

Figure 4. Contribution of the course in spoken languages and medical terminology

\subsection{Qualitative Assessment}

The qualitative evaluation was carried out by presenting a number of open questions. These included how the courses had changed the students' attitudes towards their own and other cultures; how they evaluated the course and its effectiveness; and what their suggestions were for improving the framework. Content analysis had been done which revealed a number of central themes; changing attitudes, cultural intelligence, exposure to cultural similarities and differences.

\subsubsection{Attitudes}

Exposure to new cultural content appears to have helped students rethink their attitudes toward their own and other local cultures. The students reported their intention to change attitudes and views they had held about different people and their own cultures. In addition, they noted that a change in their attitudes also included giving more respect, appreciation and attention to people from other cultures.

Student 70: "The course [Transcultural Nursing Course] helped me know how to behave with others who are 
different from me and how to discover more consideration and adapt myself to the other".

Student 99: "The course added a lot of knowledge that I did not have and changed my prejudices about people and their customs".

\subsubsection{Cultural Intelligence}

The courses improved the students' cultural awareness, their cultural knowledge, and to some extent the cultural skills that together make up the cultural intelligence of the health professional. These changes were not equal for all participants but can nevertheless be seen at different levels for a large number of participants.

Student 60: "There is no doubt that the courses provide more knowledge about the other and promote a deep acquaintance and understanding of different cultures and knowledge of the roots and sources of cultural customs"

Student 104: "In addition to being more knowledgeable and aware of other cultures around me, I know more about the cultural identity of both myself and others".

\subsubsection{Cultural Similarity and Identity}

Students were surprised to discover the degree of cultural similarity revealed during the courses. This similarity is expressed in common values, customs and social norms, pedagogy and vocabulary. Moreover, the students noted the similarities in the rationale behind various cultural and religious practices presented by their classmates from different cultures, such as circumcision practices in various religions, the prohibition of certain foods, the religiously motivated practice of visiting the sick, ritual purity and rites of passage. This similarity serves to promote a sense of partnership, closeness and respect for the values and symbols of the other. Understanding the rationale behind cultural symbols and norms strengthens personal cultural identity and respect for different cultures.

Student 64: "[The course] gave more meaning to customs ... I was less involved and now it is more important for me to connect to my culture and understand more".

\section{Discussion}

The purpose of the model was to impart knowledge and cultural awareness and develop communication skills as part of the development of the cultural competence of nursing students. Students reported an improvement in their general cultural knowledge, attitudes and cultural sensitivity in the therapeutic session they had taken part in. Particularly important was the improvement in students' attitudes towards the other cultures with whom they come into contact in their daily lives, both personal and professional. However, a difference in the degree of improvement between Arab and Jewish students was found, where Arab students reported a greater improvement in their knowledge and attitudes than their Jewish counterparts, not only with respect to Jewish culture but also with respect to their own Arab culture. This difference can be explained in terms of a society with a dominant Jewish majority and an ethnic and cultural Arab minority. These power differences influence the process of cultural learning, in which the minority feels a stronger need to learn more as part of the process of acculturation and integration into the larger society.

It is important to note that the positive change in attitudes is also expressed in the granting of respect, appreciation and attention to the components of the other's culture - values, customs, language and symbols. The learning experience also revealed students' lack of knowledge about their own culture, especially among Arab students. Enriching this knowledge led to changes in perspective and more respect and appreciation both in terms of personal growth and of strengthening cultural identity. This can contribute to a more positive integration among cultures, especially when the similarities between different cultures, such as similar values, customs, beliefs and language, are revealed.

We also found that experiential learning is important and contributes to the development of students' cultural intelligence as part of cultural competence. Using a variety of methods and tools developed by the students themselves created a social atmosphere of multiculturalism among the students and enabled more meaningful internalization and learning. Although the model does not pretend to teach the students new languages, the acknowledgement of different languages, their sources and characteristics was achieved and the vocabulary, concepts, and sentences used in encounters between nurse and patient in different settings and situations were enriched.

\section{Conclusions}

Our main conclusion is that the process of developing the cultural capacity of caregivers must begin as early as possible during their professional training. It is important to integrate cultural considerations throughout the 
nursing education process. It is also important to develop an educational system focused on cultural competence at both the theoretical and the practical and experiential level. This system must be accompanied by a systematic evaluation of the process and the results not only at the end of the training but also during the professional life of nurses. We further conclude that interactive experiential learning is the most effective method for promoting cultural competence, in which students take an active and central role in the process of acquiring cultural knowledge.

\section{References}

American Association of Colleges of Nursing. (2008). Preparing a culturally competent nursing workforce $\begin{array}{lllll}\text { initiative. } & \text { Retrieved } & \text { September } & 26, & \text { from }\end{array}$ http://www.aacnnursing.org/Portals/42/AcademicNursing/CurriculumGuidelines/Cultural-Competency-Bac c-Tool-Kit.pdf?ver=2017-05-18-143552-023

Anderson, K.L. (2004). Teaching cultural competence using an exemplar from literacy journalism. Journal of Nursing Education, 43, 253-259.

Avni, S., \& Averbach, A. (2017). Health Equity in all Policies (HEIAP). Manual for planning and evaluating health policies based on equality. The department of strategic and economic planning, Jerusalem: The Israeli Ministry of Health (in Hebrew).

Ballantyne, J. (2008). Cultural competency: Highlighting the work of the American Association of Colleges of Nursing-California Endowment Advisory Group. Journal of Professional Nursing, 24(3), $133-134$. https://doi.org/10.1016/j.profnurs.2008.04.002

Calvillo, E., Clark, L., Ballantyne, J.E., Pacquiao, D., Purnell, L.D., \& Villarruel, A.M. (2009). Cultural competency in baccalaureate nursing education. Journal of Transcultural Nursing, 20(2), 137-145. https://doi.org/10.1177/1043659608330354

Campinha-Bacote, J. (2002). The process of cultural competence in the delivery of healthcare services: A model of care. Journal of Transcultural Nursing, 13(3), 181-184. https://doi.org/10.1177/10459602013003003

Campinha-Bacote, J. (2003). The process of cultural competence in the delivery of healthcare services: A culturally competent model of care (4th ed.). Cincinnati, OH: Transcultural C.A.R.E Associates.

Coleman-Burns, P., Porter, C., Villarruel, A., \& Gerding, G. (2005). Essential diversity and multicultural competencies in University of Michigan School of Nursing undergraduate and graduate core curriculum. Curriculum Committee Subcommittee/Task $\quad$ Force. $\quad$ Retrieved from http://www.nursing.umich.edu/research/mesa/index.html

Davidhizar, R., \& Giger, J.N. (2001). Teaching culture within nursing curriculum using the Giger-Davidhizar model of transcultural nursing assessment. J Nurs Educ., 40(6), 282-4.

Giger, J., \& Davidhizar, R. (2002) Transcultural assessment model. Journal of Transcultural Nursing, 13(3), 185-188. https://doi.org/10.1177/10459602013003004

Giger, J.N., \& Davidhizar, R.E. (2008). Transcultural nursing: Assessment and intervention (5th ed.). St. Louis: Mosby/Elsevier.

Hearnden, M. (2008). Coping with differences in culture and communication in health care. Nursing Standard, 23(11), 49. https://doi.org/10.7748/ns2008.11.23.11.49.c6726

Jagosh, J., Boudreau, J.D., Steinert, Y., MacDonald, M.E., \& Ingram, L. (2011). The importance of physician listening from the patients' perspective: enhancing diagnosis, healing and the doctor - patient relationship. Patient Education and Counseling, 85(3), 369-374. https://doi.org/10.1016/j.pec.2011.01.028

Kardong-Edgren, S., \& Campinha-Bacote, J., (2008). Cultural competency of graduating US bachelor of science nursing students. Contemp. Nurse, 28, 37-44. https://doi.org/10.5172/conu.673.28.1-2.37

Kardong-Edgren, S., Cason, C., Walsh Brennan, A.M., Reifsnider, E., Hummel, F., Mancini, M., \& Griffin, C. (2010). Cultural competency of graduating BSN nursing students. Nurs. Educ. Perspect, 31(5), 278-285.

Leininger, M. (2002). Culture care theory: A major contribution to advance transcultural nursing knowledge and practices. Journal of Transcultural Nursing, 13(3), 189-92. https://doi.org/10.1177/10459602013003005

Leininger, M., \& McFarland, R.M. (2002). Transcultural Nursing: Concepts, theory, research and practice (3rd ed.). Crawfordsville: McGraw- Hill Companies.

Lerner-Zechut, A. (2015). Cultural competence in mental health in Israel. The organization for leading practices. 
The department of strategic and economic planning, mental health services. Jerusalem: The Israeli Ministry of Health (In Hebrew).

Lipson, J.G., \& Desantis, L.A. (2007). Current approaches to integrating elements of cultural competence in nursing education. Journal of Transcultural Nursing, 18, 10S. https://doi.org/10.1177/1043659606295498

McClimens, A., Brewster, J., \& Lewis, R. (2014). Recognizing and respecting patients' cultural diversity. Nursing Standard, 28(28), 45-52. https://doi.org/10.7748/ns2014.03.28.28.45.e8148

Ministry of Health, the department of strategic and economic planning. (2014). Manual for Cultural Accessibility in the Health System. Jerusalem: The Israeli Ministry of Health (in Hebrew).

Papadopoulos, I. (2006). Transcultural Health and Social Care: Development of culturally competent practitioners. London: Churchill Livingstone: Elsevier.

Papadopoulos, I., Tilki, M., \& Lees, S. (2004). Promoting cultural competence in healthcare through a research based intervention. Diversity in Health and Social Care, 1(2), 107-15.

Purnell, L. (2002). The Purnell model for cultural competence. Journal of Transcultural Nursing, 13(3), 193-196. https://doi.org/10.1177/10459602013003006

Reyes, H., Hadley, L., \& Davenport, D. (2013). A comparative analysis of cultural competence in beginning and graduating nursing students. ISRN Nurs. https://doi.org/10.1155/2013/929764

Samovar, L.A., Porter, R.E., \& McDaniel, E.R. (2010). Communication Between Cultures. Wadsworth Cengage Learning, Boston, USA. $\quad$ Retrieved from https://wsiz.rzeszow.pl/pl/Uczelnia/kadra/asiewierska/Documents/Communication\%20between\%20cultures .pdf

Singleton, K., \& Krause, E.M. (2010). Understanding cultural and linguistic barriers to health literacy. Kentucky Nurse, 58(4), 4-9.

Worrell-Carlisle, P.J. (2005). Service learning: A tool for developing cultural awareness. Nurse Educator, 30, 197-202. https://doi.org/10.1097/00006223-200509000-00006

Zafrir, H., \& Nissim, S., (2011). An evaluation of a student-led multi-language course for Israeli nursing students. Diversity in Health and Care, 8, 251-5.

\section{Copyrights}

Copyright for this article is retained by the author(s), with first publication rights granted to the journal.

This is an open-access article distributed under the terms and conditions of the Creative Commons Attribution license (http://creativecommons.org/licenses/by/4.0/). 